\title{
Seasonal dynamics in fish distribution and abundance revealed by an acoustic survey in coastal waters of the Suzu Area, Kochi Prefecture, Japan
}

Yanhui Zhu

Q2 Graduate School of Environmental Science, Hokkaido University, Japan, zhuyanhui0817@eis.hokudai.ac.jp

Kenji Minami

Estuary Research Center, Shimane University, Japan

Yuka Iwahara

Marine Fisheries Research and Development Center (JAMARC), Fisheries Research and Education Agency, Japan

Kentaro Oda

Marine Fisheries Research and Development Center (JAMARC), Fisheries Research and Education Agency, Japan

Koichi Hidaka

Marine Fisheries Research and Development Center (JAMARC), Fisheries Research and Education Agency, Japan

See next page for additional authors

Follow this and additional works at: https://jmstt.ntou.edu.tw/journal

Part of the Fresh Water Studies Commons, Marine Biology Commons, Ocean Engineering Commons, Oceanography Commons, and the Other Oceanography and Atmospheric Sciences and Meteorology Commons

\section{Recommended Citation}

Zhu, Yanhui; Minami, Kenji; Iwahara, Yuka; Oda, Kentaro; Hidaka, Koichi; Hoson, Osamu; Morishita, Koji; Tsuru, Sentaro; Hirota, Masahito; Shirakawa, Hokuto; and Miyashita, Kazushi (2021) "Seasonal dynamics in fish distribution and abundance revealed by an acoustic survey in coastal waters of the Suzu Area, Kochi Prefecture, Japan," Journal of Marine Science and Technology. Vol. 29: Iss. 2, Article 6.

DOI: $10.51400 / 2709-6998.1086$

Available at: https://jmstt.ntou.edu.tw/journal/vol29/iss2/6

This Research Article is brought to you for free and open access by Journal of Marine Science and Technology. It has been accepted for inclusion in Journal of Marine Science and Technology by an authorized editor of Journal of Marine Science and Technology. 


\section{Seasonal dynamics in fish distribution and abundance revealed by an acoustic survey in coastal waters of the Suzu Area, Kochi Prefecture, Japan}

\section{Acknowledgements}

This research received funding from the Marine Fisheries Research and Development Center, Japan Fisheries Research and Education Agency (Empirical Research Project for Marine Fisheries Resource Development: Set-net in Suzu, Kochi prefecture, Fiscal Year 2017). We also thank Masahiko Hamada for navigating the research vessel and the preparation of research cruise.

\section{Authors}

Yanhui Zhu, Kenji Minami, Yuka Iwahara, Kentaro Oda, Koichi Hidaka, Osamu Hoson, Koji Morishita, Sentaro Tsuru, Masahito Hirota, Hokuto Shirakawa, and Kazushi Miyashita 

Japan

\author{
Yanhui Zhu ${ }^{a, *}$, Kenji Minami ${ }^{b}$, Yuka Iwahara ${ }^{c}$, Kentaro Oda ${ }^{c}$, Koichi Hidaka ${ }^{c}$,

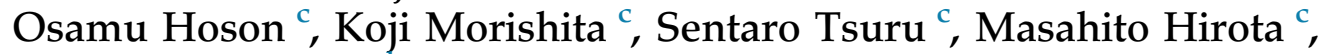 \\ Hokuto Shirakawa ${ }^{d}$, Kazushi Miyashita ${ }^{\text {e }}$ \\ ${ }^{a}$ Graduate School of Environmental Science, Hokkaido University, Japan \\ ${ }^{\mathrm{b}}$ Estuary Research Center, Shimane University, Japan \\ ${ }^{\mathrm{c}}$ Marine Fisheries Research and Development Center (JAMARC), Fisheries Research and Education Agency, Japan \\ ${ }^{\mathrm{d}}$ Japan Sea National Fisheries Research Institute, Japan Fisheries Research and Education Agency, Japan \\ ${ }^{\mathrm{e}}$ Field Science Center for Northern Biosphere, Hokkaido University, Japan
}

\begin{abstract}
For Japan's fishery, it is essential to conduct sustainable and efficient fishery owing to the decline in fish catch as well as the fisher population. To obtain information that contributes to sustainable and efficient fishery, we researched appropriate set-net locations with regard to fish distribution, abundance, and environmental characteristics. We conducted surveys from 2017/5 to 2018/2 in the Suzu coastal area, Kochi Prefecture, where the only main industry is set-net fishery. We investigated the seasonal relationships between fish school characteristics, including distribution and size, and marine environmental conditions in the Suzu coastal area, using a quantitative echo sounder (KSE300 SONIC, 38 $\mathrm{kHz}$ ) and other devices. We observed that every season showed similar trends in the horizontal structure; fish densities were higher on the coast side, and in some seasons, these were higher at approximately $2000 \mathrm{~m}$ offshore. In addition, fish densities were higher in seas at depths up to $30 \mathrm{~m}$. Set-net fishery is conducted in Suzu District at $300 \mathrm{~m}$ from the shore and at a depth of approximately $35 \mathrm{~m}$. The point of installation of set-nets is based on fish school distribution. In our study, we determined the most appropriate set-net installation points. This study not only provides a scientific basis for point selection but could also enhance the existing fishery that is limited to an aging fisher population and catch instability.
\end{abstract}

Keywords: Quantitative echo sounder, Fish distribution, Marine environment, Seasonal dynamics, Set-net fishery

\section{Introduction}

S outhern Shikoku, Japan, which is adjacent to the Pacific Ocean, is under the influence of the Kuroshio Current. The distribution and size of fish schools migrating to the surrounding sea remarkably fluctuate seasonally and annually according to the distribution of the Kuroshio Current system water [5]. The coastal zone of the southwestern region of Kochi in southern Shikoku (Fig. 1) represents seawaters under a major influence of fluctuations in the Kuroshio Current path [20]. In addition, it is influenced by the entry of a low-temperature ocean current from the

Received 28 April 2020; revised 20 July 2020; accepted 18 August 2020.

Available online 21 May 2021.

* Corresponding author.

E-mail address: zhuyanhui0817@eis.hokudai.ac.jp (Y. Zhu). 


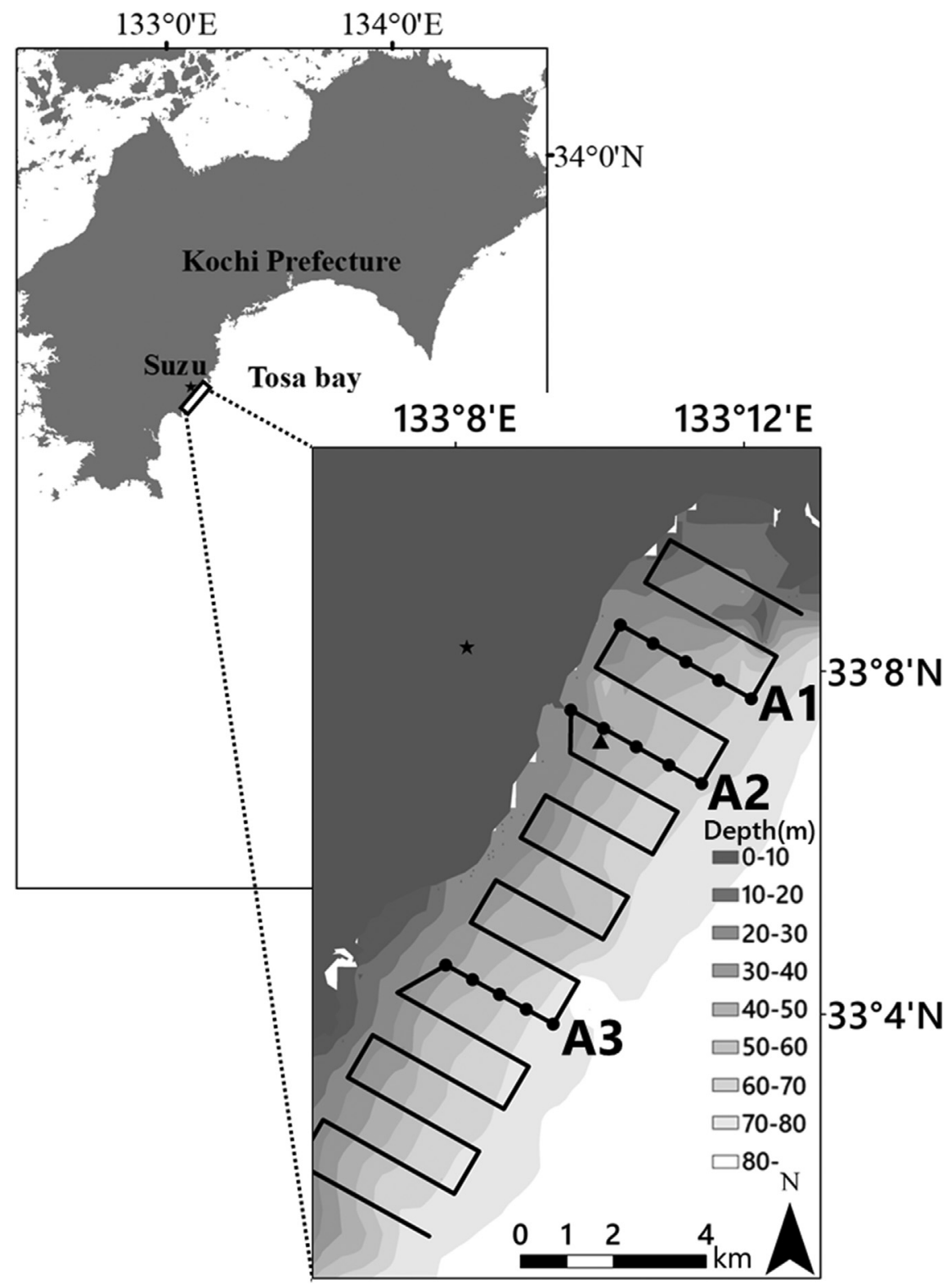

Fig. 1. The study area, Suzu, on the Kochi prefecture coast of Tosa bay. The solid line shows the hydroacoustic survey transects, with a total length of $64 \mathrm{~km}$. Three measurement paths (A1-3) were used by the environment survey and the closed circles indicate where the CTD points were conducted. The triangle marks indicate the location of the Set-net.

Bungo Channel to the sea area during spring [4]. Such diverse currents influence the marine environment of the coast throughout the year. However, changes in the distribution and size of fish schools in the coastal zone, which are related to environmental changes, are yet to be clarified.

The population of Kuroshio-cho Suzu district in southwest Kochi is approximately 90, and largescale set-net fishery (here after referred to as set-net fishery) is the only major industry in the district. The average age of the fishers is $60-64$ years. The industry is contending with the typical challenge of the Japanese coastal fishery in that the continuity of fishery is at risk due to the aging fisher population and catch instability. In addition, the decline in setnet fishery in Suzu district could adversely affect the economy of the region.

To facilitate efficient set-net fishery and ensure continuity, set-nets should be installed at locations where catch efficiency and fisher workload are well balanced. It is critical to investigate fish schools that migrate to the surrounding sea areas of set-net and the changes in their distribution characteristics. In 
addition, set-net fishery is a passive fishing method, and shifting installation points is challenging. Consequently, catch quantity in set-net fishery is highly dependent on the distribution and size of fish schools in the area where nets are installed [14]. In the current set-net fishery in Suzu district, the closest point of the guide net to the land is $300 \mathrm{~m}$ from the shore, the main body net is installed $500 \mathrm{~m}$ from the shore at approximately $35 \mathrm{~m}$ depth. However, there is no scientific basis confirming that it is in an optimal position for high fish catch. Thus, investigating changes in the distribution and size of fish schools around set-net could facilitate a stable fishery in Suzu district in the future.

Quantitative echo sounders can locate indicators of fish school distribution parameters, including density [1], they have been used extensively to evaluate the quantities of fish resources. In the present study, we aimed to investigate seasonal variations in the distribution of fish schools using a quantitative echo sounder in the coastal zone of Suzu district. The marine environment of study area was also investigated at the same time. In addition, the relationship between the distribution of fish schools and the marine environment was examined based on catch by the set-net fishery and the environmental conditions.

\section{Materials and Methods}

The study location was the coastal zone of Suzu District, which is in the west of Tosa Bay (Fig. 1). The quantitative echo and environmental assessments were performed four times in May (spring), August (summer), and November (fall) in 2017, and in February 2018 (winter). The study area was relatively large $(5 \times 25 \mathrm{~km}$, depth: approximately 10-70 $\mathrm{m})$. Acoustic survey was conducted on the fishing boat (Suzumaru, 9.91 tons) used for set-net operations. A quantitative echo sounder (KSE300; SONIC Inc., Tokyo, Japan) with a frequency of $38 \mathrm{kHz}$ was installed on the starboard side to conduct the fish school distribution survey (Table 1). The survey was carried out during the daytime when pelagic fish, which are the main target species of set-net

Table 1. The settings used for every on the quantitative echo sounder (KSE300) with a $38 \mathrm{kHz}$ transducer.

\begin{tabular}{ll}
\hline Variable & Specification \\
\hline Transducer & T-178 \\
Frequency $(\mathrm{kHz})$ & 38 \\
Beam type & Split \\
Beam width $\left({ }^{\circ}\right)$ & 8.5 \\
Pulse width $(\mathrm{ms})$ & 0.6 \\
Ping rate(s) & 0.2 \\
\hline
\end{tabular}

fisheries, are likely to form schools [7]. A transducer was installed under water ( $1 \mathrm{~m}$ from the surface) to reduce the influence of air voids generated by the contact of the hull with the sea surface on the transmission and reception of acoustic waves and generate noise [18]. The vessel was operated at 5-7 knots when collecting the acoustic data. Positional information was collected using a differential GPS (Trimble Inc.) to obtain positional information of the fish schools. The positional data was saved on a PC in sync with the acoustic data. For reliability, the quantitative echo sounder was calibrated before initiating each survey. The acoustic data were collected by sailing along a defined survey path (Fig. 1 ). The survey path was perpendicular or parallel to the coast, with the only deviations due to avoidance of other installed nets.

Area backscattering strength $(S a)$ and volume backscattering strength $(S v)$ values were extracted from the acoustic data to determine fish density and distribution [13]. To eliminate the effects of noise due to microorganisms such as phytoplankton and zooplankton (in addition to suspended matter), the threshold $S v$ value was set at $-60 \mathrm{~dB}$ [8], and regions with weaker echo were excluded from the present study. Furthermore, only the fish school was targeted in the present study, echoes other than those of the fish school were not included in the analysis. Therefore, the extracted $S a$ and $S v$ values reflect the echoes of the regions which only included the fish school. Since the extraction of a fish school considers the body length or density of target species [2], a $1 \times 1 \mathrm{~m}$ resolution was set for minimum candidate length/height of fish schools. This resolution represents the lowest reaction magnitude corresponding to small target fish such as sardines or mackerels (Fig. 2). In addition, we determined whether our samples were from the same fish school by reviewing the measurements when examining cross sections of the echoes of fish school close to each other. The maximum vertical/horizontal linking distance for a single fish school was set to $5 \mathrm{~m}$ both in the vertical and horizontal directions (Fig. 3). The echoes were extracted based on average $S a$ from the surface to bottom with $10 \mathrm{~m}$ horizontal intervals, and average $S v$ involved $10 \mathrm{~m}$ horizontal and vertical intervals using Echoview v7.1 (Sonardata Tasmania Pty Ltd.).

To determine fish school distribution trends, the horizontal and vertical structures of the fish school distribution were clarified using $S a$ and $S v$ values. In addition, we investigated the horizontal structure of fish school distribution; $S a$ obtained was expressed on a map using ArcGIS v10.2 (Esri Inc.). The distance from the shore to the fish school, $L$, was 


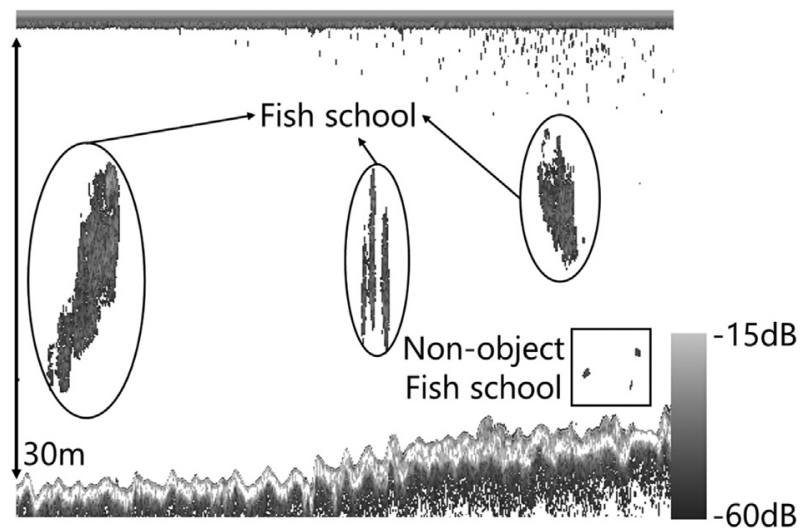

Fig. 2. The echogram shows object fish schools and non-object fish schools.

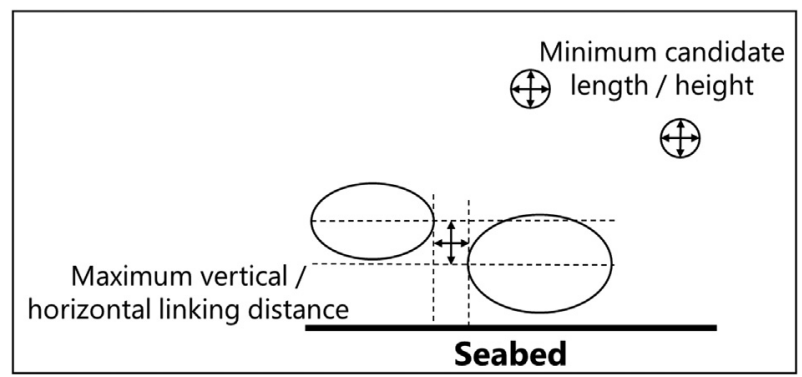

Fig. 3. The mechanisms of fish school detection using Echoview. Solid circles indicate the fish school and arrows indicate distance.

calculated. $S a$ obtained from the echo measurements and the calculated distance, $L$, were used to estimate the horizontal structure of fish school distribution using a generalized additive model (GAM) that assumed a normal distribution. GAM was executed using the gam function in the "mgcv" package of $\mathrm{R} v$ 3.5.0 ( $\mathrm{R}$ Core team, 2017). In addition, to reveal the vertical structure of fish school distribution, the relationship between the distribution information, $S v$, of the fish school and the distribution depth, $D$, of the center of the fish school, was estimated using GAM, similar to the method used to estimate the horizontal structure.

In each study month, the fish species composition and the percentage of each fish species was obtained using fish catch data of the set-net in the investigated coastal area to examine occurrence trends of fish classes inhabiting or migrating to the location. In addition to set-net catch, species composition in the fish schools was examined by angling in each season immediately after the fish school distribution data were obtained using echo measurements. However, fish catch data could not be obtained during summer, as set-net fishing was not operational. During summer, fish species inhabiting the coastal study areas were confirmed by trolling.

Water temperature and salinity were measured simultaneously with each echo investigation using a conductivity-temperature-depth profiler (RINKO Profiler, ASTD102, JFE Advantech Co. Ltd., Japan). Three measurement paths were set up in total - one on each of the southern (A3) and northern (A1) sides of the Set-net, and one at the center of the inspected coastal area (A2). Environmental data were measured at five points along the measurement paths (Fig. 1). A vertical cross-section diagram of each line was created based on the water temperature and salinity data. The contour function in "akima" and "fields" packages in R v3.5.0 (R Core team, 2017) was used to illustrate the diagram.

\section{Results}

\subsection{Seasonal variation in fish school distribution}

In spring, acoustic data were acquired at approximately 8,047 points in the entire study area. Fish school echoes were observed at 318 acoustic data points. Strong echo responses of $-40 \mathrm{~dB}$ or more were observed at 99 points, accounting for more than $30 \%$ of the points where fish school echoes were observed (Table 2). In spring, a single school with a high density was broadly distributed from the coastal zone to the offshore zone (Fig. 4 a). In addition, when the horizontal distribution trends of the fish schools obtained by GAM were examined (Table 3), the echo generated by the fish schools were particularly strong $(\mathrm{P}<0.01)$ at the shore and approximately $2,000 \mathrm{~m}$ from the shore in the locations where the fish schools were confirmed (Fig. $5 a)$. With regard to the vertical distribution trends,

Table 2. Total data points of Sa (area backscattering strength) and data points of each fish school within the reflection intensity range in each season.

\begin{tabular}{llllllll}
\hline & Total data points & \multicolumn{5}{l}{ Data points of fish school } \\
\cline { 3 - 7 } & & Total points & $\sim-50 \mathrm{~dB}$ & $-50 \mathrm{~dB} \sim-40 \mathrm{~dB}$ & $-40 \mathrm{~dB} \sim-30 \mathrm{~dB}$ & $-30 \mathrm{~dB} \sim-20 \mathrm{~dB}$ \\
\hline Spring & 8047 & 318 & 137 & 82 & 75 & 24 \\
Summer & 7359 & 146 & 15 & 81 & 48 & 2 \\
Autumn & 6806 & 131 & 59 & 58 & 11 & 3 \\
Winter & 6383 & 504 & 285 & 105 & 102 & 12 \\
\hline
\end{tabular}



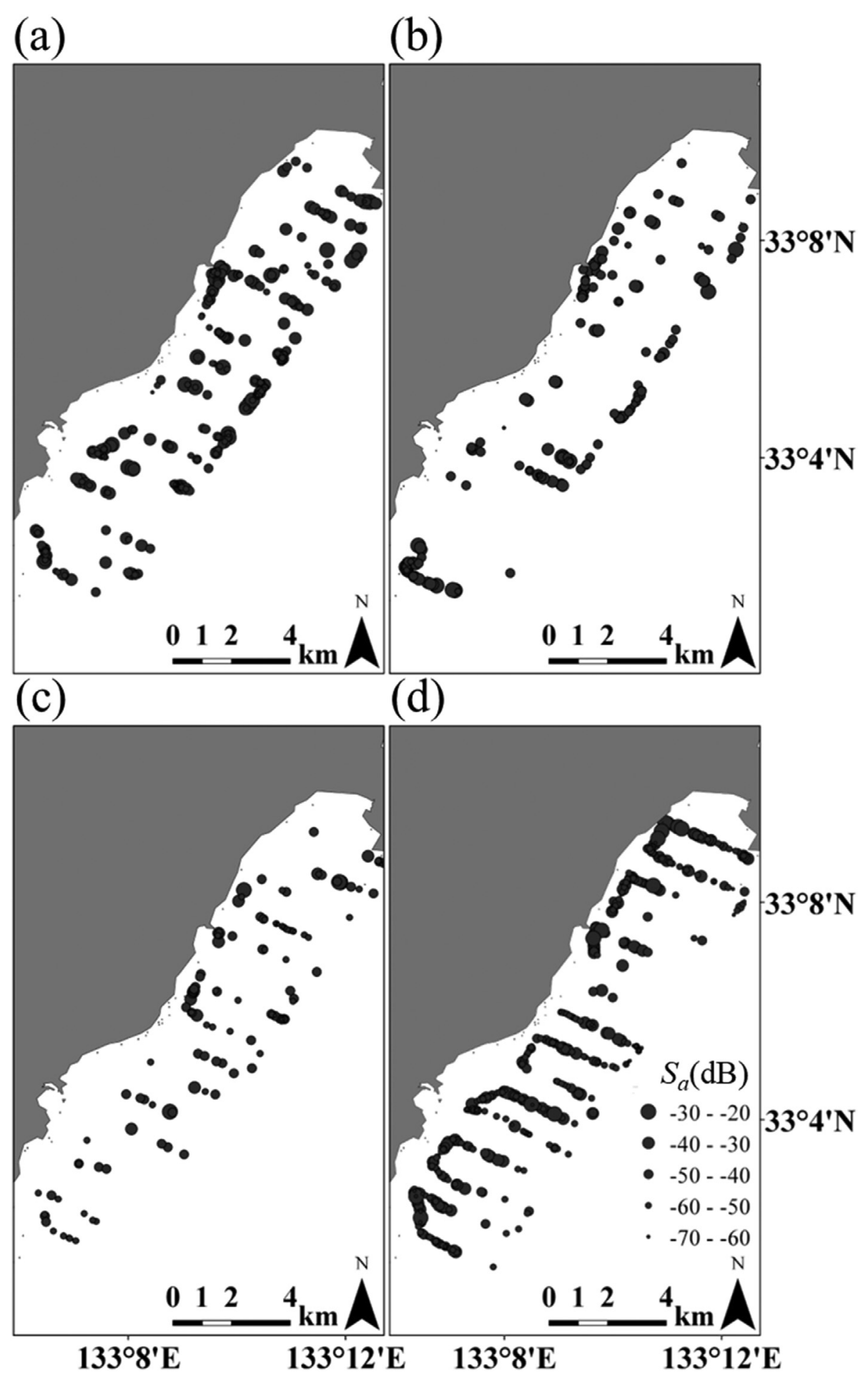

Fig. 4. Seasonal variation in acoustic fish abundance, expressed as the area backscattering strength, Sa. Closed circles show the area backscattering strength of fish school (a. Spring, b. Summer, c. Autumn, d. Winter).

the echo of fish schools was strongest from the surface layer to a depth of $30 \mathrm{~m}$ (Fig. 6a). In particular, strong responses of -30 to $-40 \mathrm{~dB}$ was observed at depths around $20 \mathrm{~m}(\mathrm{P}<0.01)$.
During summer, the number of fish schools decreased in the entire sea region compared to the spring. Among the 7,359 points in the entire study area, fish school echoes were confirmed at only 146 points. Among these, strong fish school echoes of 
Table 3. Statistical results of the relationship between Sa and distance from shore $(L)$, relationship between $S v$ and depth $(D)$ in each season. The edf coefficients indicate effective degrees of freedom. The values of $s(L)$ and $s(D)$ indicate the approximate significance of the smooth terms.

\begin{tabular}{|c|c|c|c|c|c|c|}
\hline & \multicolumn{3}{|l|}{ Spring } & \multicolumn{3}{|l|}{ Summer } \\
\hline & Estimate & edf & p-value & Estimate & edf & $\mathrm{p}$-value \\
\hline Intercept (Sa) & -45.520 & - & $<0.01$ & -41.150 & - & $<0.01$ \\
\hline & - & 4.492 & $<0.01$ & - & 5.312 & 0.096 \\
\hline Intercept (Sv) & -48.389 & - & $<0.01$ & -44.758 & - & $<0.01$ \\
\hline \multirow[t]{3}{*}{$\mathrm{s}(\mathrm{D})$} & - & 3.888 & $<0.01$ & - & 1.000 & $<0.01$ \\
\hline & \multicolumn{3}{|l|}{ Autumn } & \multicolumn{3}{|l|}{ Winter } \\
\hline & Estimate & edf & p-value & Estimate & edf & $\mathrm{p}$-value \\
\hline Intercept (Sa) & -48.685 & - & $<0.01$ & -49.020 & - & $<0.01$ \\
\hline $\mathrm{s}(\mathrm{L})$ & - & 2.916 & $<0.01$ & - & 6.448 & $<0.01$ \\
\hline Intercept (Sv) & -48.901 & - & $<0.01$ & -48.681 & - & $<0.01$ \\
\hline$s(D)$ & - & 3.716 & $<0.01$ & - & 7.555 & $<0.01$ \\
\hline
\end{tabular}

$-40 \mathrm{~dB}$ or more were observed at 50 points, while fish school echoes of $-30 \mathrm{~dB}$ or more were observed at only two points, which represented a decrease by 24 points compared to the observations in spring (Table 2). In addition, compared to spring, the number of the fish school decreased during summer. The trend was particularly pronounced in the south side of the study area (Fig. $4 \mathrm{~b}$ ). There was no difference in the distribution of fish schools in the horizontal structure based on the distance from the shore $(\mathrm{P}<0.01)$ (Fig. 5b) (Table 3$)$. In addition, with regard to vertical distribution trends, fish school echoes were not observed at depths $<10 \mathrm{~m}$. At depths $>10 \mathrm{~m}$, fish school echoes decreased gradually with increasing depth $(\mathrm{P}<0.01$, Fig. $6 \mathrm{~b})$.

During fall, fish school numbers were low, similar to those during summer. Among the 6,806 acoustic data points, 131 included fish school echoes. In addition, the strength of the echoes were less than those during summer, and strong fish school echoes of $-40 \mathrm{~dB}$ or more were only observed at 14 points (Table 2). In addition, the fish school echoes weaker than $-40 \mathrm{~dB}$ were broadly distributed from the coast to the offshore during fall. Fish school echoes were weaker in the southern side than those in the northern side (Fig. 4c). The results of the analyses of the horizontal distribution trends in fish schools using GAM (Table 3) revealed that fish school echoes were strong on the shore and 2,000 $\mathrm{m}$ from the shore $(\mathrm{P}<0.01$, Fig. 5c). With regard to the vertical structure of the fish school distribution, fish school echoes became weaker with increasing depth (a)

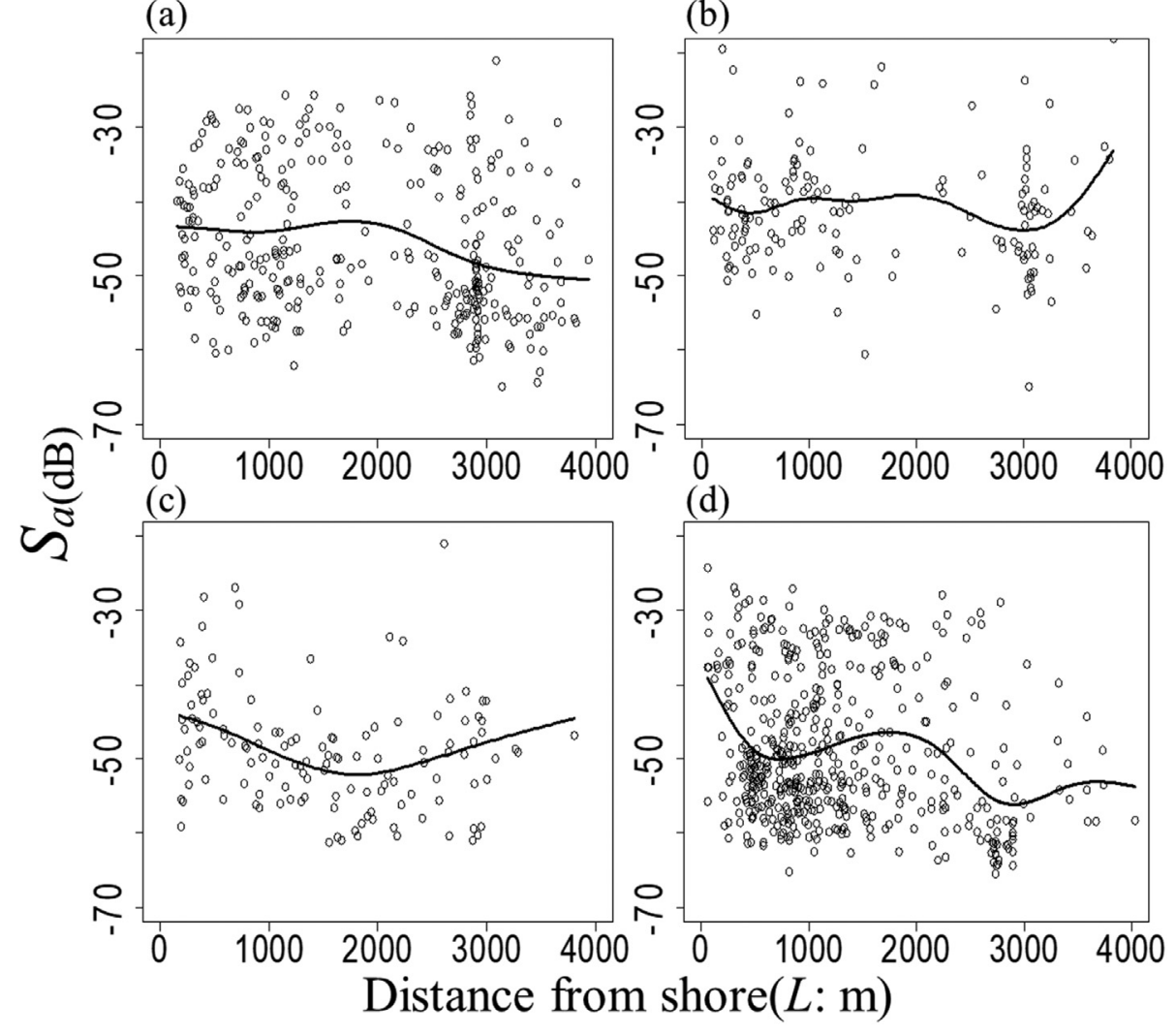

Fig. 5. Seasonal variation of fish distribution in the horizontal structure expressed as the relationship between Sa (area backscattering strength) and $L$ (distance from shore) based on GAM (generalized additive model). The solid line shows the estimated line of fish density (Sa). The open circles show the measured value of $S a$ (a. Spring, b. Summer, c. Autumn, $d$. Winter). 
(a)

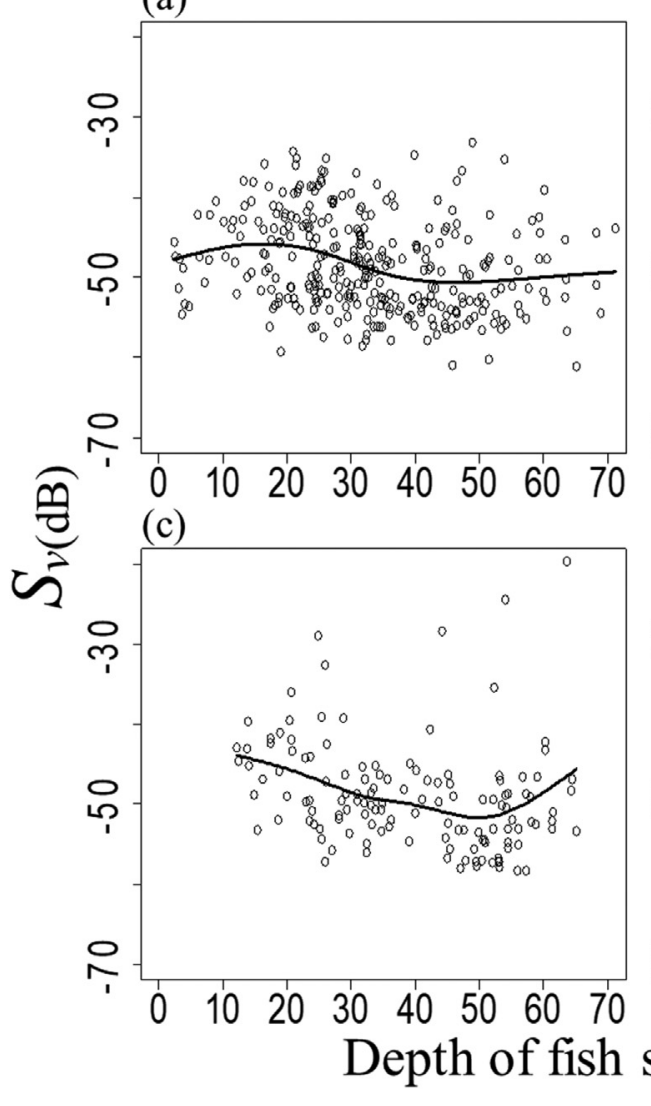

(b)

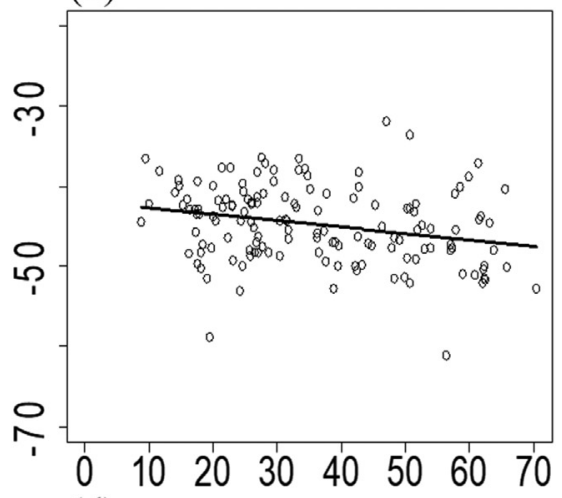

(d)

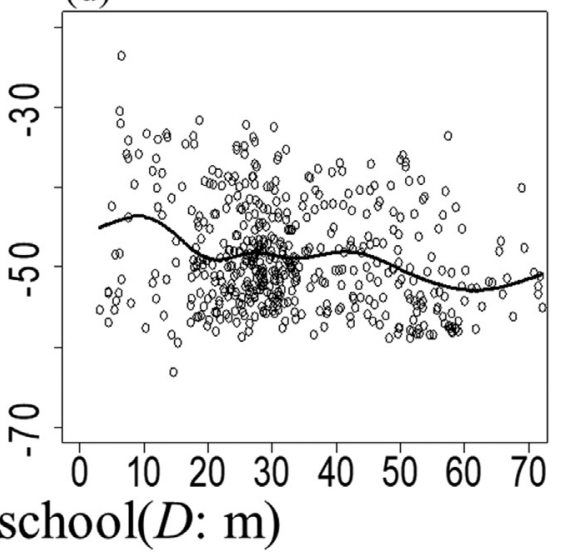

Fig. 6. Seasonal variation of fish distribution in the vertical structure expressed as the relationship between Sv (volume backscattering strength) and D (depth of fish school) based on GAM (generalized additive model). The solid line shows the estimated line of fish density (Sv). The open circles show the measured value of Sv (a. Spring, b. Summer, c. Autumn, d. Winter).

(up to $50 \mathrm{~m}$ ) but became stronger at depths greater than $50 \mathrm{~m}(\mathrm{P}<0.01$, Fig. $6 \mathrm{c})$.

The winter season had the largest number of fish schools. Among the 6,383 points investigated, fish school echoes were observed at 504 points. In addition, the highest number of strong fish school echoes (of $-40 \mathrm{~dB}$ or more) were observed in the winter season, at 114 points (Table 2). Fish school echoes were also the strongest in the winter season, and the strongest of these fish school echoes were observed in the shore side (Fig. 4d). Analysis of the fish school echo horizontal distribution trends by GAM (Table 3) revealed that stronger echo responses were observed on the shore side when compared to $500 \mathrm{~m}$ offshore. In addition, fish school echoes were strong between 1,000 and 2,000 m offshore ( $\mathrm{P}<0.01$, Fig. $5 \mathrm{~d})$. In the vertical direction, fish school echoes were the strongest at approximately $10 \mathrm{~m}$, and became weaker at $10-20 \mathrm{~m}$. However, there was no major change in fish school echoes at a depth of 20-40 m. At depths $>40 \mathrm{~m}$, fish school echoes became even weaker $(P<0.01$, Fig. $6 d)$.
The results showed that the number of fish schools were larger during spring and winter than during summer and fall (Table 2). In addition, the number of fish schools were larger at the shore side than offshore throughout the year. Furthermore, during spring and winter, when there were large numbers of fish schools, the fish school echoes were also strong at points approximately $2,000 \mathrm{~m}$ from the shore (Fig. 5). Meanwhile, the whole fish school vertical distribution varied considerably across seasons. In spring and winter, fish school echoes were stronger on the surface layer up to a depth of $30 \mathrm{~m}$ compared to deeper layers. During summer, the fish school echo strength decreased with increasing depth. Similar trends were observed during fall, except that during fall, the strength increased at depths $>50 \mathrm{~m}$ (Fig. 6).

\subsection{Seasonal variation in fish species composition}

During spring, middle to shallow water fish belonging to the class Actinopterygii were dominant in the set-nets. These include Big-eye sardine 
Table 4. Species composition, weight of fish in Set-net catches, and number of fish in fishing and trolling catches in each season.

\begin{tabular}{|c|c|c|c|c|c|c|c|c|}
\hline \multirow[t]{2}{*}{ Fish species } & \multicolumn{2}{|l|}{ Spring } & \multicolumn{2}{|l|}{ Summer } & \multicolumn{2}{|l|}{ Autumn } & \multicolumn{2}{|l|}{ Winter } \\
\hline & $\begin{array}{l}\text { Set-net } \\
\text { Weight }(\mathrm{kg})\end{array}$ & $\begin{array}{l}\text { Fishing } \\
\text { Number }\end{array}$ & $\begin{array}{l}\text { Trolling gear } \\
\text { Number }\end{array}$ & $\begin{array}{l}\text { Fishing } \\
\text { Number }\end{array}$ & $\begin{array}{l}\text { Set-net } \\
\text { Weight }(\mathrm{kg})\end{array}$ & $\begin{array}{l}\text { Fishing } \\
\text { Number }\end{array}$ & $\begin{array}{l}\text { Set-net } \\
\text { Weight }(\mathrm{kg})\end{array}$ & $\begin{array}{l}\text { Fishing } \\
\text { Number }\end{array}$ \\
\hline Atlantic horse mackerel & 3497 & 1 & & 6 & 1529 & 15 & 6849 & \\
\hline Yellowtail & 2954 & & 8 & 1 & & & & 1 \\
\hline Big-eye sardine & 2664 & 27 & & 3 & & & & \\
\hline Anchovy & & 35 & & & & & & 4 \\
\hline Japanese pilcha rd & 2582 & 5 & & & & & & \\
\hline Club mackerel & 1710 & 101 & & 2 & 671 & 1 & 830 & 4 \\
\hline Common dolphinfish & 990 & & & & & & & \\
\hline Red barracuda & & & & 1 & 3942 & & 3412 & \\
\hline Bonito & & & 53 & & 1751 & & & \\
\hline Great amberjack & & & 5 & & 942 & & & \\
\hline Atlantic cutlassfish & & & & & & & 1369 & \\
\hline Swordtip squid & & & & & & & 1000 & \\
\hline Others & 3778 & 2 & 2 & 10 & 2295 & 6 & 943 & 6 \\
\hline
\end{tabular}

(Etrumeus teres) and Japanese pilchard (Sardinops melanostictus), fry of Atlantic horse mackerel (Trachurus trachurus) and Chub mackerel (Scomber japonicus), Yellowtail (Seriola quinqueradiata), and Common dolphinfish (Coryphaena hippurus), accounting for more than a half of the total catch (Table 4). In the fish class confirmed by angling, sardines and fry of Chub mackerel were caught in bulk. The main species forming the fish schools were similar to those caught by set-net.

During summer, based on the fish class caught by angling and trolling, migratory fish such as Bonito (Auxis rochei), Yellowtail, and Great amberjack (Seriola dumerili) were widely distributed.

During fall, Red barracuda (Sphyraena pinguis), Bonito, adult Atlantic horse mackerel, Great amberjack, and Chub mackerel were caught by setnet. The fish species that were caught the most during fall were Red barracuda, Atlantic horse mackerel, and Bonito, accounting for $70 \%$ of the entire fish catch. In addition, Atlantic horse mackerel was caught the most by angling.

During winter, adult Atlantic horse mackerel accounted for half of all the fish classes caught by Set-net. In addition, Red barracuda, Atlantic cutlassfish (Trichiurus japonicus), and Swordtip squid (Loligo edulis) were caught in large quantities. On the other hand, Chub mackerel less than $10 \mathrm{~cm}$ in length and immature sardine were frequent in angling catches in the study area during winter, indicating that fish species composition differed to the fish catch trends by set-net.

Fish species composition varied considerably across seasons; some fish classes were distributed across all four seasons, such as Atlantic horse mackerel. In addition, in some seasons the catch trends based on set-net fishery were different from those of angling.

\subsection{Seasonal variation of the marine environment}

In spring, the water temperature range was $4^{\circ} \mathrm{C}$, with the lowest temperature of $17{ }^{\circ} \mathrm{C}$ near the seabed and the highest of $21^{\circ} \mathrm{C}$ near the sea surface (Fig. 7). The salinity range was 0.8 with a minimum of 34.0 near the seabed and 34.8 near the sea surface (Fig. 8). In addition, water temperature changed at a depth of approximately $30 \mathrm{~m}$ in study area, forming a thermocline. The thermocline tended to be stronger in the northern side of the study area than the south side.

During summer, major changes were observed in the vertical water temperature and salinity in the study area. The lowest water temperature was $19^{\circ} \mathrm{C}$ close to the seabed and the highest temperature was $30^{\circ} \mathrm{C}$ near the sea surface. The lowest salinity was 33.1 near the sea surface and the highest was 34.6 in the vicinity of the seabed. The differences in temperature and salinity were much greater in the summer to the spring. The differences between surface recording and near the sea bottom were 11 ${ }^{\circ} \mathrm{C}$ and 1.5, respectively. In addition, a major thermocline was observed in the study area, and the depth of the surface layer mixolimnion tended to be deeper on the southern side. The thermocline was formed from $10 \mathrm{~m}$ to $30 \mathrm{~m}$ on the north side and from $30 \mathrm{~m}$ to $50 \mathrm{~m}$ on the south side.

The water temperatures at all investigation points were lower during fall than during summer. The water temperature in the north side of the study area and around the set-net was maintained at approximately $21{ }^{\circ} \mathrm{C}$ from the sea surface to the seabed. The lowest water temperature on the south side was $18{ }^{\circ} \mathrm{C}$ near the seabed, with the highest being $22{ }^{\circ} \mathrm{C}$ in the vicinity of the sea surface. With regard to salinity, there was no major change in the entire study area over the fall. The lowest level was 

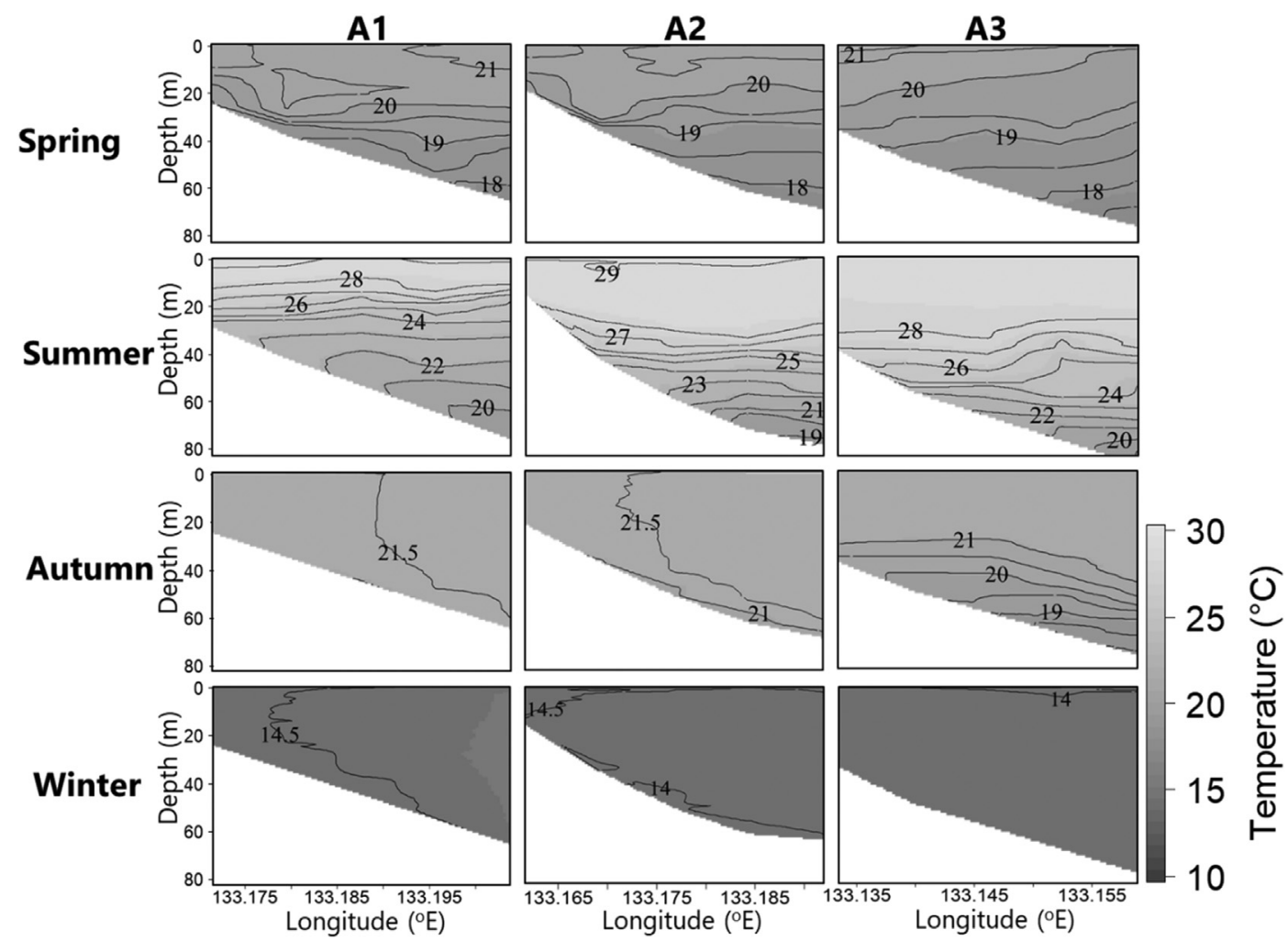

Fig. 7. Seasonal vertical distribution of temperature (in each line) as identified by the CTD surveys (refer to Fig. 1). In each panel, the solid lines show the constant-temperature line.
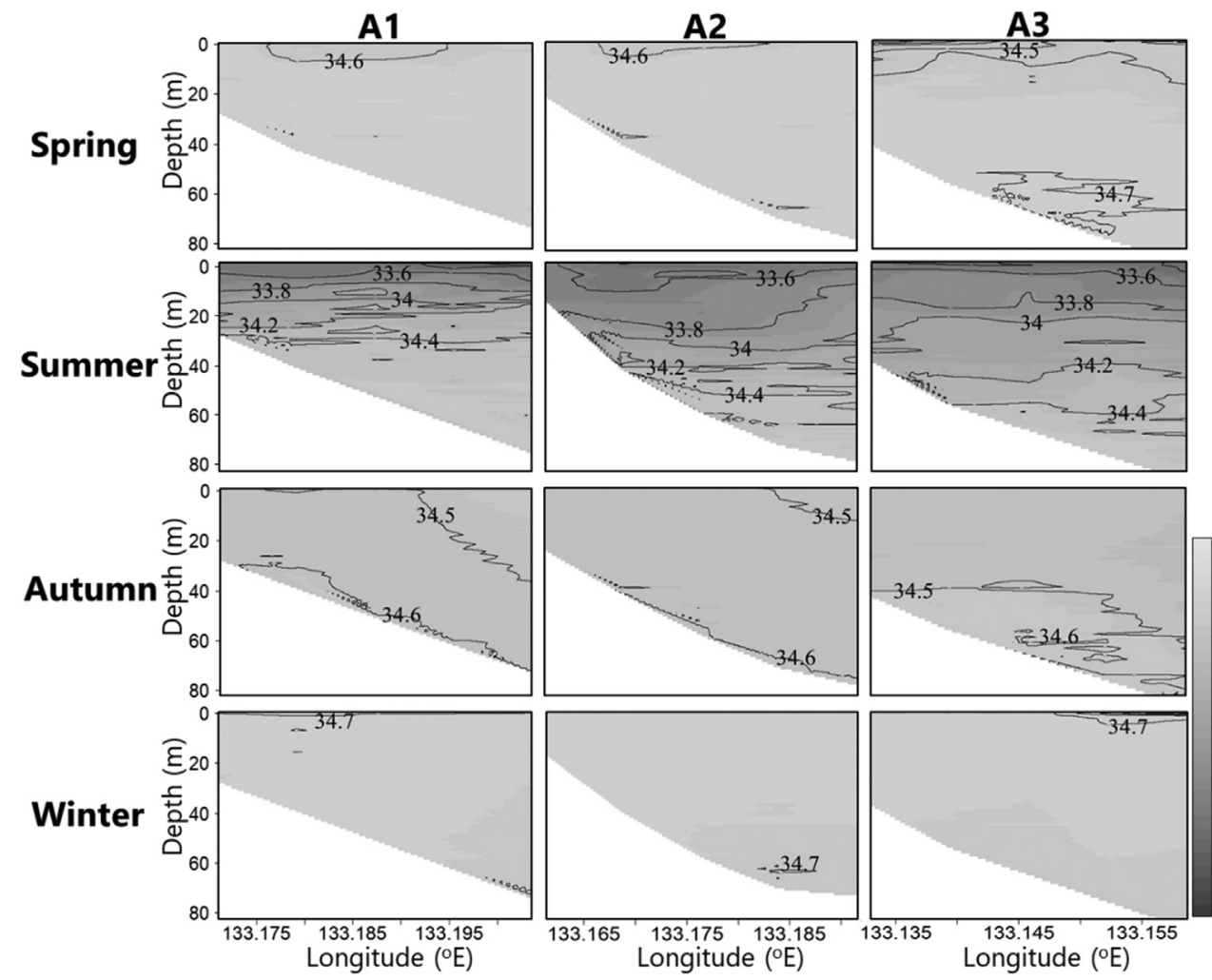

34.5

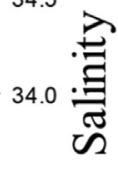

33.5

33.0

Fig. 8. Seasonal vertical distribution of salinity (in each line) as described by the CTD surveys (refer to Fig. 1). In each panel, the solid lines show the constant-salinity line. 
34.4 near the surface and the highest was 34.6 near the seabed. Compared to summer, vertical mixing was active during fall, and stratification was not observed in the north side and around the set-net. However, on the south side of the study area, a change in the water temperature was observed near the bottom layer.

During winter, the average water temperature was lower than the average water temperature during fall. The average salinity was similar. The lowest and highest temperatures in the entire study area were $13{ }^{\circ} \mathrm{C}$ and $15^{\circ} \mathrm{C}$, respectively. The salinity in the entire study area ranged from 34.7 and 34.8. Vertical mixing occured during winter, with no difference in water temperature observed between the surface and bottom layer. Similarly, salinity was almost homogeneous from the surface to the bottom.

Stratification was observed in the marine environment in spring based on the high-water temperature zone in the surface layer and the low water temperature zone in the bottom layer (separated at the depth of around $30 \mathrm{~m}$ ). Considerable stratification occurred during summer. However, such stratification was not observed during fall and winter, with no temperature difference between the surface layer and the bottom layer. From spring through winter, the highest and lowest water temperatures in the study area were $30{ }^{\circ} \mathrm{C}$ and $13{ }^{\circ} \mathrm{C}$, respectively, indicating temperate waters. In addition, with regard to salinity, there were variations based on depth during spring and summer, with salinity tending to be low during summer when compared to spring. Such differences in salinity were almost non-existent during fall and winter. Consequently, in the study area, significant stratification emerged gradually from spring to summer, with fall and winter as the transition phases.

\section{Discussion}

\subsection{Relationship between fish school distribution and fish species composition}

The dominant fish species caught by set-net and angling in spring were sardines, immature Atlantic horse mackerel and Chub mackerel, Common dolphinfish, and Yellowtail. In the fry stage, Atlantic horse mackerel inhabit the surface layer [19] and it highly prefers the coastal zone [21]. In addition, sardines and Chub mackerel fry are coastal-zone fish and they can be observed regularly near the surface layer [9]. Common dolphinfish is a warmwater fish that migrates with the Kuroshio Current, and it inhabits the surface layer, gathering around drifting seaweeds [11]. Yellowtail caught in spring is a migration group that moves and migrates seasonally to the north and south in the warm current area and is distributed at depths shallower than $50 \mathrm{~m}$ [6]. Based on the ecology of the dominant species above, the echo could have been stronger in the surface to middle layers (up to $30 \mathrm{~m}$ ) and up to approximately $2,000 \mathrm{~m}$ from the shore in spring because such multiple classes of surface-layer coastal, middle-layer, coastal, and migratory fish were dominant in the study area.

During summer, fish species with greater migratory tendencies such as Bonito, Yellowtail, and Great amberjack were confirmed in large quantities in trolling activities. In particular, Bonito accounted for $80 \%$ of the fish catch. Bonito migrates into the coastal zone and inhabits the study area off Kochi until the breeding season [16]. In addition, adult Bonito exhibited aestival northern migration and autumnal southern migration in the coastal zone of Kochi [16]. However, small Bonito migrate to the Tosa Bay coast during summer [17]. Therefore, the fish echo results of the entire study area reflected the habits of fish species with strong coastalmigration tendencies such as Bonito and different classes of the same fish species.

During fall, Red barracuda, adult Atlantic horse mackerel, and Bonito were caught by the set-net in large, quantities; they were the dominant fish species in the study area. Red barracuda tend to approach the coast in groups and live in the surface layer [12]. In addition, Atlantic horse mackerel, which highly prefers the coastal zone as fry, shifts to the bottom layer in the adult phase [19]. Our findings demonstrate that, fish schools that were stronger on the shore side of the study area were influenced by adult Red barracuda and Atlantic horse mackerel. The strong fish school echoes observed near the surface layer was associated with Red barracuda. Those schools observed at depths near the bottom layer were associated with adult Atlantic horse mackerel. In addition, adult Bonito exhibited an aestival northern migration and autumnal southern migration, and, from November, Bonito that migrated south appeared in the coastal zone of Kochi [16]. Therefore, Bonito migrating from the offshore side could have influenced the fish school echoes that intensified in the offshore side of the study area.

During winter, the strong fish school echoes on the shore side could have been from Red barracuda and adult Atlantic horse mackerel that were the dominant species among the catch, since their catch quantities accounted for more than $70 \%$ of all setnet catches. In addition, the strongest response was 
observed in the surface layer at around $10 \mathrm{~m}$. The echoes could have been from immature Chub mackerel and sardines, which are surface dwellers. This hypothesis was further supported by the angling catches, in addition to surface-dwelling Red barracuda.

Seasonal differences in the horizontal and vertical distribution of the fish school potentially reflected the ecology of the dominant fish species that varied with season. In addition, similar fish classes exhibited shifts in distribution based on growth stages, as observed Atlantic horse mackerel. The distribution characteristics of the fish schools changed as maturity stages varied, even when the same fish species was dominant.

\subsection{Relationship between fish school distribution and environment factors}

Examination of the vernal distribution of fish schools revealed that the fish school echo was strongest at approximately $20 \mathrm{~m}$. In addition, the vernal water temperature in the vertical cross section showed a thermocline at $20-30 \mathrm{~m}$. Consequently, the thermocline zone corresponded with the fish school echoes were frequently observed. Sardines, Atlantic horse mackerel fry and Chub mackerel fry that feed on phytoplankton could have gathered near the thermocline for food as primary production near a thermocline is high [3].

During summer, the water temperature was high in the study area at depths less than $10 \mathrm{~m}$, with minimal fish school echoes. Since the photosynthetic activity decreased in the surface layer in the southern area due to strong light inhibition [4]. This type of habitat is considered unfavorable for fish due to low phytoplankton levels in the high temperature layer. In addition, the appropriate water temperature for Bonito (the fish caught the most during summer) is $21-23{ }^{\circ} \mathrm{C}$ [10]. However, the aestival water temperature in the surface layer was $28-30{ }^{\circ} \mathrm{C}$. Therefore, fish school echoes were minimal in areas shallower than $10 \mathrm{~m}$ and increased at greater depths, the fish schools tended to avoid the high-water temperature layer, favoring the cooler temperature zone below it.

During fall and winter, vertical mixing occurred, with no observable variations in water temperature and salinity across depths. However, the coastal zone of the Suzu District was warm even during winter as it is under the influence of the Kuroshio Current. The optimum water temperature for Atlantic horse mackerel, most of which were caught during fall and winter, is $18-21^{\circ} \mathrm{C}$ [15]. Atlantic horse mackerel (a warm-water fish) was caught in large quantities because their temperature requirements correlated with the study area. In addition, since Atlantic horse mackerel lay eggs from January through to May in areas with a surface water temperature range from $15-25^{\circ} \mathrm{C}$ [22]. During winter, the study area could have been a favorable spawning ground for the species.

Based on the above findings, it is conceivable that the thermocline was formed in spring and summer, and fish schools gather near the thermocline. In addition, the formation of the thermocline was not observed during fall and winter due to vertical mixing. However, the study area is warm due the effect of Kuroshio Current throughout the year, allowing this area to be an appropriate habitat for warm-water fish.

\section{Future prospects}

Disparities were observed in the horizontal and vertical structures of fish school distributions across seasons. However, common trends were observed throughout the year. Horizontally, fish schools were large on the shore side within $500 \mathrm{~m}$ from the shore, or in the area approximately 2,000 $\mathrm{m}$ offshore throughout the year. The nearest location of the guide net to the landside of the set-net in Suzu District is $300 \mathrm{~m}$ from the shore. Therefore, from a horizontal perspective, the installation point of the set-net did correlate with fish school distribution on the shore side. In addition, the vertical fish school distribution structure in most season (excluding the fall) demonstrated that fish schools tended to be large and within depths of $30 \mathrm{~m}$. The main body of the set-net is fixed at a depth of approximately $35 \mathrm{~m}$. Catches have the potential to increase if the set-net is installed at locations shallower than $30 \mathrm{~m}$. This change would allow the point of installation of the set-net to be based on the fish school distribution.

Since increases in fish schools were observed in the area approximately 2,000 $\mathrm{m}$ offshore, fish catch could be increased in the future by moving the setnet offshore. This would allow the nets to catch fish species distributed in the offshore side. Alternatively, the installation of an offshore guide net may be effective if the location was based on our study findings on the horizontal and vertical distributions of fish schools. However, the Kuroshio path, which is considered to influence the marine environment of the Suzu District coast, changes annually. In addition, there are potential annual fluctuations in the fish school and their distributions in the region. In the future, potential long-term increases in catch could be investigated by examining the long-term fish school distribution characteristics and the 
relationships between seasonal variations in distribution and marine environmental factors.

When a set-net is transported offshore, since the tide offshore is more rapid than the current at the set-net installation point, effects such as a decrease in fish entering the net due net malfunctions and a loss of unloading days due to aging problem are anticipated. Therefore, in the future, it is considered necessary to conduct an appropriate survey for finding an optimum fishing ground in the offshore area such as by observing tidal currents. Furthermore, there are human aspects such as increase in workload and a lack of an adequate work force, in addition to the transportation of nets offshore and the installation of offshore lead nets. Therefore, social and economic factors that influence operations should also be taken into account when determining appropriate fishery strategies.

In the present study, we investigated the relationship between fish school distribution and marine environmental factors over a year and obtained critical insights on appropriate set-net installation points based on data acquired using a quantitative echo sounder in the sea surrounding the set-net in the Suzu District coastal zone. The Japanese coastal fishery is facing challenges such as aging fishers and fish catch instability. The challenges are not confined to set-net fishery, and studies on effective fishery strategies appropriate for local communities required. Therefore, in the future, such scientific studies will be critical for understanding the spatiotemporal distribution trends of fish schools in the marine environment.

\section{Acknowledgments}

This research received funding from the Marine Fisheries Research and Development Center, Japan Fisheries Research and Education Agency (Empirical Research Project for Marine Fisheries Resource Development: Set-net in Suzu, Kochi prefecture, Fiscal Year 2017). We also thank Masahiko Hamada for navigating the research vessel and the preparation of research cruise.

\section{Reference}

[1] Axenrot T, Hanson S. Seasonal dynamics in pelagic fish abundance in a Baltic Sea coastal area. Estuar Coast Shelf Sci 2004;60(4):541-7.

[2] Coetzee J. Use of a shoal analysis and patch estimation system (SHAPES) to characterise sardine schools. Aquat Living Res 2000;13(1):1-10.

[3] Derenbach JB, Astheimer H, Hansen HP, Leach H. Vertical Microscale Distribution of Phytoplankton in Relation to the Thermocline. Mar Ecol Prog Ser 1979;1:187-93.
[4] Ichikawa T, Hirota Y. Seasonal Changes of Primary Productivity in Tosa Bay, Japan. Oceanogr Jpn 2004;13(3):259-69 (in Japanese).

[5] Itoh S. Studies on water mass variability related to dynamics of ecosystems in the Oyashio/Kuroshio region. Oceanogr Jpn 2012;21(2):33-50 (in Japanese).

[6] Kaji K. Elucidation of migration history for effective use of yellowtail Seriola quinqueradiata resources. In: Bulletin of Kochi Prefectural Fisheries Experiment Station in 2007. vol. 105; 2008. p. 25-38 (in Japanese).

[7] Kakimoto H, Tsumura K, Noda M. Creation of Fishing Ground and Nursery by the Artificial Reef Technique. Fish Eng 1998;34(3):305-11 (in Japanese).

[8] Kang M. Current technology of fisheries acoustics based on analyzed acoustic data using SonarData's Echoview. Acoustics 2006 2006;20-22(November 2006):493-7.

[9] Kawano M. Species Composition and Distribution of Fish Larvae in the southwestern Japan Sea in 1987. In: Bulletin of Yamaguchi Prefectural Fisheries Research Center. vol. 6; 2008. p. 61-6 (in Japanese).

[10] Kitazawa N. The relationship between Catch of Frigate Mackerel (Auxis sp.) and Kurosio Path and surface temperature in Sagami bay. In: Bulletin of Kanagawa Prefectural Fisheries Research Institute. vol. 3; 1998. p. 39-42 (in Japanese).

[11] Kojima S. Fishing for Dolphins in the Western part of the Japan sea-VI, Behaviours of fish gathering around bamboo rafts (4). In: Bulletin of the Japanese Society of Scientific Fisheries. vol. 26; 1960. p. 383-8 (in Japanese).

[12] Kuwahara A, Suzuki S. Vertical Distribution and feeding Hefits of a horse Mackerel Trachurus japonicus and a Barrcuda Sphyraena pinguis Larvae in the Western Wakasa Bay. In: Bulletin of the Kyoto Institute of Oceanic and Fisheries Science. vol. 6; 1982. p. 13-7 (in Japanese).

[13] MacLennan ND, Fernandes PG, Dalen John. A consistent approach to definitions and symbols in fisheries acoustics. ICES J Mar Sci 2002;59:365-9.

[14] Miida F, Nemoto M, Takeuchi S. Statistical Study on the Catch Characteristics of Set-net Fishing Grounds in Miura Peninsular Region. J Tokyo Univ Fish 1999;86(2):55-67 (in Japanese).

[15] Nemoto $M$, Shibuya $K$, Nakano $H$, Furumi $T$, Joshima $H$ Miyazaki T, Kitade Y. The relationship between the behavior of fish school, Jack mackerel Trachurus japonicus and oceanic conditions in Tateyama Bay, Chiba Prefecture, Japan. La mer 2017;55:1-10 (in Japanese).

[16] Niiya Y. Age, Growth, Maturation and Life of Bullet Tuna Auxis rochei in the Pacific Waters off Kochi Prefecture. Nippon Suisan Gakkaishi 2001;67(3):429-37 (in Japanese).

[17] Okabayshi S. Bonito (Auxis rochei). In: Niimoto K, editor. Kochi's Fish Collection. Kochi: Libre Publishing; 1986. p. 100-4 (in Japanese).

[18] Shimmonds J, MacLennan DN. Fisheries Acoustis-Theory and Practice Sedcond Edition. Massachusetts: Blackwell Publishing; 2006. p. 63-5.

[19] Takamura S, Katayama T, Kinoshita J. Transition of catch fish and resource trends of important fishes in fixed net of Sagami Bay. In: Bulletin of the Kanagawa Prefectural Fisheries Technology Center. 7; 2014. p. 65-71 (in Japanese).

[20] Toyoshima S, Shimamura K. Coastal Current in Tosa Bay and South Region of Kii Channel. In: Technical bulletin on hydrography. 17; 1999. p. 20-5 (in Japanese).

[21] Yamada T. Observation on the Distribution and the Fishing Grounds of Jack mackerel Trachurus japonicus (TEMMINCK et SCHLEGEL) in the Japan Sea. In: Bulletin of the Faculty of Fisheries, Nagasaki University. vol. 28; 1969. p. 111-30 (in Japanese).

[22] Yoda M, Ohshimo S, Hiyama Y. Estimation of the Spawning Ground of Jack Mackerel in the East China Sea Based on the Catch Statistics and Biometric Data (1). In: Bulletin of the Japanese Society of Fisheries Oceanography. 68; 2004. p. 20-6 (in Japanese). 